\title{
A Reflection on "Divinatory Conventions in Late Shang China" and the Grammar of the Oracle-Bone Inscriptions
}

\author{
Ken-ichi Takashima \\ University of British Columbia, Vancouver, BC, Canada \\ kenichi.takashima@ubc.ca
}

\begin{abstract}
This paper questions Keightley's claim that the divinatory conventions followed in the Diviner Li 歷-Group charges were different from those followed in the Diviner Bin 賓-Group charges. The paper relies in part on what may be shown as an objective guideline, i.e., what is commonly referred to as "presupposition", a supposition made prior to any utterance or sentence. The paper also addresses the problem of $q i$ 其 and the negatives used with or without it.
\end{abstract}

\section{Keywords}

divinatory conventions - oracle-bone inscriptions - grammar - presupposition - qi 其

\section{$1 \quad$ Introduction ${ }^{1}$}

It was an inspiring experience to have re-read Professor David N. Keightley's monograph-length paper entitled "Divinatory Conventions in Late Shang China: A Diachronic and Contextual Analysis of OracleBone $Q i$ 其 and Related Issues" (in BCL 13.1; original ms. 236 pp. dated 19 July, 1995). I have learned much from it. Due to various limitations, personal or otherwise, I cannot address all the different issues Keightley (abbreviated hereinafter as "K") deals with, but there are a few of them that may be worth scrutinizing further.

First, K's "thick description" and "thick analysis" of the relevant materials, scholarship, theoretical orientations, and meticulous examination is very impressive. He has amassed a vast number of examples of $q i$ and related words from the corpus of the Shang oracle-bone inscriptions (OBI) available at the time of writing. It demands a closer look at the way in which $q i$ and other related words and expressions are used. His paper offers sharp observations and logical arguments which, when taken as a whole, present the appearance of carefully crafted hypotheses about a few important issues related to the function and meaning of $q i$. Their clarification ought to be the goal of all the analysts of OBI.

K's analysis and arguments also seem to contain several weak points. The most important of these is what we fear as misuse and application of some linguistic concepts, such as anaphora, reference, deixis,

1 This is a revised version of Takashima (1995), an unpublished paper.

(C) KEN-ICHI TAKASHIMA, 2020 | DOI:10.1163/2405478X-01302010

This is an open access article distributed under the terms of the CC BY-NC 4.o license. 
modification, negation — which, strictly speaking, is a grammatical phenomenon, though semantic properties cannot be divorced from it—and nominalization (e.g., K's "quasi-wei/hui" proposal, see infra). All these and more will be discussed in this paper.

There is what we perceive to be an ill-advised appeal to the syntactic function of several pertinent words, especially the existential/possessive verbs, copulas, and negatives. What is needed is the proper application of such linguistic concepts as presupposition, modality, aspect, and negation. The privation seems to have led those in the field of OBI studies to take on an agnostic attitude towards our earlier proposals on these subjects, to which $\mathrm{K}$, however, seems most sympathetic.

The rest of this paper will be devoted to discussing these weak, as well as some strong, points and to provide further details of our own interpretations of some pertinent grammatical and semantic issues. In so doing we will be much concerned with what the Shang diviners and the kings thought what they were saying, and this through English translation of the original Shang Chinese (perhaps not ideal, but unavoidable).

We begin with the subject matter of anaphora and deixis. Simply stated, anaphora is a resumption of a word or phrase, an antecedent, carrying old (shared) information, and occurring in successive clauses. When the anaphoric element, the most common one being a pronoun, is identified with its antecedent, they constitute a coreferend - also called coreferent - in the mutually coreferential relationship. Deixis involves a set of words, sometimes displaying morphologically distinct features, constituting the form and meaning. It often yields a deictic or demonstrative system in a more or less self-evident way, such as demonstratives "this/that" in English, *g-/*k- vs. *t- in Old Chinese as in 其/之 (Mei Tsulin 1981; Yue 1998), $\mathrm{k}$-/s-/a- as in kore, sore, are, kono, sono, ano, etc. in Japanese; personal pronouns like "I/you/he/she/they"; adverbs like "here/there" (place), "now/then" (time). Strictly speaking, however, anaphora and deixis should be distinguished. $\mathrm{K}$ is correct in taking $q i$ as anaphoric, pronominal, and genitive (accepting my proposal in Takashima 1996; Takashima is abbreviated hereinafter as "T"). This interpretation is applicable, but only to certain specific, environments. $\mathrm{K}$ does not seem to be applying it consistently. He construes $q i$ as having anaphoric reference to any noun, noun phrase, verb, verb phrase, or even sentence. This becomes confusing when it is allowed to have a referential function in what we deem syntactically difficult environments. He does not discuss $q i$ in deictic ways systematically.

In short, $\mathrm{K}$ seems to have built an impressive "expository castle" occasionally on unstable "theoretical sands", and at least a few pillars supporting the weight of the castle require, in our view, reinforcement. Specifically, K's major thesis that the divinatory conventions followed in the Diviner Li 歷-Group Charges were different from those followed in the Diviner Bin 賓-Group Charges is, we believe, untenable. But this depends on various interpretive, mostly linguistic, factors, and the reader is invited to join in critical examination.

We start with K's Li-group charges. He thinks that they employed a set of divinatory conventions different from those of the Bin 宆-group, specifically Model Bin-group (典宆), charges. The latter, in fact, forms the foundation of my own past work on $q i$, one that might have been slanted. It seems, however, that even if certain divinatory conventions of the Li-group—-specifically Li-1, Li-2 and Li-Cao (歷一, 歷二, 歷草) inscriptions, differed from those of the Bin-group, they do not have substantial bearing on the grammar and semantics of the inscriptional language of either group. They are roughly coeval, and unless there 
were extensive differences, dialectal ${ }^{2}$ or otherwise (e.g., isolated foreign language influences such as Austroasiatic, the language of the Yi 夷 people, possibly the ancestors of the Shang themselves), ${ }^{3}$ they may be treated as the same stock of language. In the case of $q i$, however, we are willing to give the benefit of the doubt, thus proceeding to examine how qi be best interpreted. Below, we give our translations of a few key examples. We use K's example numbers for ease of reference, followed by discussion.

\title{
$3 \quad Q i$ 其 “in this case”, Reference, Referend, and Presupposition
}

\author{
p. 56 [81A]: 甲戌卜:乙亥雨. 允雨. \\ Crack-making on jiaxu (day 11): “On yihai (day 12) it will rain.” [Verification:] It surely did rain.
}

[81B]: 甲戌卜:丙子雨.

Crack-making on jiaxu (day 11): "On bingzi (day 13) it will rain."

There is no $q i$ in $[81 \mathrm{~A}]$ or $[81 \mathrm{~B}]$. Thus, modality and aspect are not overtly expressed. Yet, on the basis of the use of the adverb yun 允 'surely, really', ${ }^{4}$ we can detect the existence of a presupposition about the diviner's desire for rain on the yihai day, wishing that it would rain. The same applies to [82A]-[82E].

The negative counterpart of the Bin-group charge-pair, [56A] (己卯卜靔貞: 不其雨一HJ $902=$ Bingbian 235.1) has qi, while its positive counterpart, [56B] (已印卜靔貞: 雨一Ibid. = Bingbian 235.2) does not. We would translate [56A] as: "It might not be going to rain" (examples [14A, B] in T 1994: 506). Qi in $[56 \mathrm{~A}]$ interacts with, specifically responding to, a presupposition, in such a way as to "weaken" the effect of negation in the charge. ${ }^{5}$ The presupposition here must have been that rain was desired because the positive charge is $y u$ 雨, a single-word sentence (or a verb phrase) with an ambient or zero subject. Also, in the verb phrase bu qi yu, literally, "not/qi (aspect = going to, happen to, about to)", and the kind of modality assignable to $q i$ must surely be to the left side of the scale "possibility/certainty". ${ }^{6}$ In contrast

2 There seems to be some uncertain, to be carefully examined, cases in which the word order of the double-object construction (involving indirect and direct objects), is different in the Li-group from a great majority of the Bin-group inscriptions. However, the Bin-group diviner named Que 殸—which we prefer to read as Nan 䌾 (on the basis of paleographical evidence; T 2010: II.4O-41; 2019: 25-27) — fluctuates in his use of the double-object construction. Takashima and Yue (2000: 30) suggested that Nan, having come from the region other than the capital (Yindu 殷都), possibly south (Appendix A, \#1), was trying to learn the $\mathrm{S}+\mathrm{O}_{\text {indirect }}+\mathrm{O}_{\text {direct }}$ word order in the capital but had not quite mastered it, slipping into the $\mathrm{S}+\mathrm{O}_{\text {direct }}+$ $\mathrm{O}_{\text {indirect }}$ word order.

3 Fu Sinian (1935); Mei Tsu-lin and Jerry Norman (1976); Pulleyblank (1983, 1995).

4 We have used the following set of rules: after a foreign word or an expression, usually Chinese, single quotes, like 'xyz', are used to indicate that xyz is a translation or equivalent in English. Double quotes, like "xyz", are used to indicate that xyz is someone else's translation or equivalent. Also, "xyz" are used to indicate that xyz is "special", sometimes called "scare quotes" used to draw the reader's attention. Furthermore, we observed the "hierarchical bracketing rule", namely, avoiding such notations as "abc "xyz" def" or 'abc 'xyz' def' - these will be expressed as "abc 'xyz' def" or 'abc "xyz" def'. This also applies to the brackets so that " $(x y z(x y z))$ " will be written as "(xyz [xyz])"; likewise "[xyz [xyz]]" will be written as "[xyz (xyz)]". The standard use of the brackets, both (xyz) and [xyz], is also adopted.

5 This is an extension of K's original idea that there were "stronger" and "weaker" charges (K 1992), but this does not seem always applicable. We will have more to say on this later.

6 Here we exclude two other modal scales that may be appealed to in other situations: those of "intention and wish" and of "necessity and obligation". These two scales involve an element of "will" on the part of the subject, while the "possibility/certainty" scale does not, since the natural phenomenon of rain is not within the sphere of human control. Thus, "rain" by itself, more accurately the "ambient/dummy" subject of it, would be characterized as [-will]. An interpretation like "It shall not be 
to our translation of [56A], K's is: "Crack-making on jimao (day 16), Que divined: 'It will not in this case rain'” Let us examine this translation (interpretation).

By taking 其 as "in this case" in [56A], K appears to assume that "this" refers to a verb phrase 不 ... 雨 'not ... rain'. What does the "this" refer to is actually not clear, but if taken by itself the only candidate we can see is “不雨”. Similarly, it is not clear if the reference is, instead, to "the jimao day cracking officiated by the diviner Que who made this charge", a topical noun phrase. If it was the latter, qi could have referred to this topical noun phrase that easily permits referencing. Perhaps in order to maintain "lexical logic", K has translated [56B] 已印卜殸貞: 雨. 王占 [曰]: 其雨隹王. 王午允雨 $(H J 902=$ Bingbian 235.2), replete as it is with a prognostication by the king and a verification, as follows: "Crack-making on jimao, Que divined: 'It will rain.' The king read (the cracks): 'This raining will be on the ren-day'." (Emphasis in italics is ours.) So here qi's reference is to a single-word sentence or a VP (verb phrase). Either way it is clear that the reference is to $y u$ 雨 in the charge introduced by zhen 貞 translated "divined" by K (which we follow in this paper). We thus get four possible referends: (1) a verb phrase “不雨”; (2) the direct-object clause of zhen; (3) a topic; and (4) a single-word sentence or a VP with an ambient or zero subject. If 其 were taken to refer to all these referends at once, it becomes ambiguous, and the existence of multiple referends by a single pronominal word would deprive the word of its original function.

We think there is an alternative, much simpler, interpretation. First, the qi in bu qiyu has nothing to do with reference. Here it is flanked by the negative $b u$ and the verb $y u$; and if the verb were not a stative or eventive verb as $y u$ is, but a dynamic/mutative one like $f a$ 伐 'attack' as in $[142 \mathrm{~B}], 7$ the negative used for the dynamic/mutative verbs is $f u$ 弗 or $w u$ 勿 (though this is never followed by $q i$ ). In these constructions, there seems no other possibility but to construe $q i$ as an adverb. This is the result of a historical process known as "lexicalization" (cf. n. 13). That is, originally the grammatical function of $q i$, which we take as (likely deictic) pronominal-genitive (T 1994; 2020), generates various semantic overtones. We will later discuss an issue more involved than what is described above because $\mathrm{K}$ responded to an earlier version of this paper with new analyses and new interpretations (letter dated August 9, 1995).

If one accepts the existence of presupposition underlying in a great majority of divinatory utterances, e.g., [56A, B], there must have been such a presupposition as the rain was desired in the single $y u$ 雨 charge. Conversely, "not/qi/rain" 不其雨 structure shows that rain was undesirable. This is what scholars refer to as "Serruys' rule of 其" expressing "undesirable" alternative, a rule that is not inherent in the word 其 itself. To an unspoken question "Will it be qi raining?", an appropriate answer in the declarative mode would have been something like: "It might not be going to rain," a "weak" charge that still leaves open the possibility of (going to) rain, and this in spite of the fact it is undesirable from the diviner's standpoint. This sort of "skepticism" may have been motivated by the "balanced dualism" or "metaphysical balance" discussed in $\mathrm{K}$ (1988: 374-376). This is a topic worth exploring further in the future.

We should note the difference between $[56 \mathrm{~A}, \mathrm{~B}]$ and $[81 \mathrm{~A}, \mathrm{~B}],[82 \mathrm{~A}-\mathrm{E}]$ in that while the king participates in the prognostications of the Bin-diviner group inscriptions like [56B], he does not in the Li-group

going to rain," a kind of injunction directed to some nature spirit seems to be wide of the mark here, though such an injunctive meaning may be cogent in other contexts (as in prognostications).

7 K's translation of [142B] (旨弗其伐出盢羅) reads: “Zhi will not in this case attack Youguluo.” We would offer “Zhi might not (be able to) attack Youguluo (successfully)." The verb 伐 used here is what we call a "success verb" which is distinguished from “attempt verb". Seemingly the same verb 伐 is also negated by $w u$ 勿 as in $H J 6513,6514,6547,6555$, etc. In these cases, 伐 is specified as an attempt verb. (For more on this distinction, see n. 11.) The distinction is important because for one thing the choice of a negative is determined by it. The success verbs invariably dictate the *p-type negatives such as $f u /{ }^{*}$ pət 弗 and $b u /$ pə 不, and the attempt verbs the *m-type negatives such as $w u{ }^{* *}$ mət 勿 and $w u /{ }^{*}$ mə 母. Given sufficient context, we can account for the choice of a negative; it is almost completely predictable. 
inscriptions. This can be observed in [81A, B], [82A-E]. Also, the divination charges are often couched in ways that are modally neutral, balanced, "equal-informational" - albeit of course one is positive the other negative. (We shall have more to say on this issue later.) Thus, we see a $y u$ vs. buyu opposition as in $[82 \mathrm{~B}$, $\mathrm{C}]$ and $[82 \mathrm{D}, \mathrm{E}]$. But this cannot deny the presence of a presupposition because, even if modally neutral on the surface, we can still tell in a great majority of cases which alternative the Li-group diviners, or any-other-group diviners for that matter, desired. ${ }^{8}$ It is also in consonance with any kind of divination by human (for which much literature is available). As K notes on p. 57 (n. 112), the most common Li-group charge-pair about rain is bu yu vs. qi $y u$, the latter with a clearly expressed modality and prospective aspect, and the former being a specific manifestation of the presupposition that rain was not desired, even though this is inscribed on the "desirable right hand side" of this plastron (i.e., an exception out of not all that many others). The latter, qiyu, is also a specific manifestation of the presupposition that rain was not wanted. This happens to agree with "Serruys' rule of $q i$ ", but this is only a surface phenomenon, and there are "exceptions" (e.g., HJ 12973).

We believe that buyu can fairly accurately be translated as: "It will not happen to rain", "It is not going to rain", or even, given certain conditions, "It is not about to rain." The indeterminacy of these different translations here is due to the difficulty of capturing the degree to which any precise aspectual meaning may be assigned.

There is also the problem of capturing modal overtones in both Shang Chinese and English. This is closely related with the interpretation of the negatives which have to be considered in conjunction with the unnegated verbs in the positive. According to our theory, the negative $b u$ is stative/eventive/nondynamic (T 1988; revised version in Itō and T 1996: I.364-382; T 2020). In certain specific contexts such as in the prognostications, we can translate qiyu as: "It will surely happen to rain", "It will surely be going to rain", or even "It will surely be about to rain." But if one member of a charge pair is preferable to the other member-judged on the basis, e.g., of the existence of a certain specific, unspoken, presupposition, also taking the desirable-right and the undesirable-left orientation on the turtle plastron into consideration (though this is not infallible) — then the human will may be superimposed on a natural phenomenon like rain, wind, snow, shine, etc. This would yield a somewhat stilted translation like: "It shall be going to rain"-which Nivison (1996: 267) detests and thinks it simply means "it is going to rain". But my meaning is a kind of peremptory nuance-or, to use Ezra Pound's rendition of the same phrase in the Shijing, "Oh, rain!" (rain desired). The negative counterpart of qi yu ought to be *wu yu 母雨 “*It should not happen to/be going to rain', but we could not find any example for reasons that we cannot understand. But because the use of 积 limited in comparison with the other negatives in the body of Shang OBI, the absence of *wuyu 母雨 does not seem potent enough to reject our theory on the nature of this negative altogether. It just means that the negative $\$$ is not as fully supported with its actual examples as the other negatives are.

There are, however, a few cases of “quasi-negative counterpart” that reads wu yu 勿雨 'don't let it rain' (HJ 11506r, 13029, 13038, 13040, etc.). ${ }^{9}$ The 勿 is not a stative/eventive negative, but a dynamic/mutative

8 Let us consider a kind of "display inscriptions" (cf. K 1978: 46, n. 90): [142A], [142B], and [142C] (of which [142B] has already been translated in $\mathrm{n} .7$ by both K and T). Note that in [142A] (... 旨其伐出疊羅), the positive counterpart, also has $q i$, and it is perfectly clear that even though $[142 \mathrm{~A}]$ and $[142 \mathrm{~B}]$ are modally neutral because the effect of $q i$ in both charges must be equal, it was $[142 \mathrm{~A}]$ that expressed what the diviner desired, especially when the verb $f a$ 伐 is taken as a "success verb". [142C] (王占曰:吉. 我伐隹丁 'His Majesty, having prognosticated, declared: "It is auspicious. That we will [be able to] attack [Youguluo successfully] will be on a ding-day") seems to confirm it. It also supports, in the final analysis, the "success verb" reading of the verb $f a$.

9 One might expect that 勿雨 'don't let it rain' would occur exclusively in the prognostications because unlike the charges 
one, so that we cannot translate 勿雨 as “* It should not happen to rain," “* It should not be going to rain," or “*It should not be about to rain." In any event, all these points are our partial, though perhaps still imperfect, response to the question $\mathrm{K}$ has raised at the bottom of p. 57: "Why the Li-group diviners routinely placed the $q i$ in the positive charge $q i y u$, rather than in the negative charge $b u y u$, is not entirely clear." But if we allow a certain specific presupposition on the part of the diviner before he uttered charges, we can generally tell why not only the Li-group diviners but other group diviners, and indeed any speakers of Shang Chinese, expressed the way they did.

In the Introduction, we have mentioned some problems with K's treatment of the negatives. One example is found on pp. $5^{8-59}$, where he does offer an explanation for the Li-group diviners having been primarily concerned with the "no rain" charge (不雨), followed by the "rain" charge (雨). He cites the "pacifying the wind" and "pacifying the rain" inscriptions that he thinks support his explanation. However, these ning feng 寧風 and ning yu 寧雨 charges are completely different from the grammatical opposition of a positive and negative charge. Apparently, these ning feng and ning yu charges were made under apprehensions of the wind and rain bringing some impediments to the Shang. Ning 'to appease, pacify' is a ritual verb done in an attempt to ward off whatever impediment they thought existed or was imminent. ${ }^{10}$

p. 59 [丙] 辰卜䌾貞: 我受㯟年.

[83A]: Crack-making on bingchen (day 53), Nan divined: "We will (be able to) ${ }^{11}$ receive (= harvest) a (good) millet crop."

they often expressed the wishes of the prognosticators, often the king. However, the HJ 13029 case (to cite but one example) occurs in the charge. The rubbing of $H J 13029$ is not all that clear, but its original, Jiabian 3419, shows that 勿雨 is preceded by 貞 'tested'. HJSW transcribes it as: 貞允不雨 “*Tested: It surely will not rain', but it is most probably incorrect. Actually, the use of “勿 + Verb" in so many other charge pairs in which the positive is just Verb expresses the wishes of diviners. The diviner's presupposition must have been the negated Verb is what was desired. As will be discussed more fully later, we make a distinction between the sacrificial and ritual verbs. Ning is a ritual verb because it does not govern any sacrificial object (commonly some animal victim) as a direct object. In the case of ning feng 寧風, we sometimes find sacrificial victims, but they are not used as direct objects but as instrumental objects. To cite just one example, we find in HJ 34137 the following inscription: 甲戌貞: 其寧風三羊三犬三豕 'On jiaxu (day 11) divined: (We) will conduct the pacifying-the-wind ritual with (the use of) three sheep, three dogs, and three pigs'. One may replace our translation "with the use of ..." with the phrase "by sacrificing ...". That is what the Shang may have intended. But the point is that these sacrificial victims are not the direct object of the verb ning.

11 We have supplied in parentheses "be able to" to indicate that the verb shou 受 is specified as a "success verb" distinguished from an "attempt verb" (see n. 7). However, when the same bone graph writes the word shou 授 'to grant, confer', the success or attempt verb distinction does not seem applicable. This may be due in part to the subject having been someone who the Shang diviners thought unable to control his action, like Di 帝 'Supreme deity'. A pair of charges like the following will illustrate this point:

辛亥卜䌾貞: 伐台方, 帝授[祐]. ‘Crack making on xinhai (day 48), Nan divined: “When (we) attack the Gong, Di will confer upon (us) divine succor".' (HJ 6271)

貞: 帝不我其授祐. 'Di might not be conferring divine succor upon us.' (Ibid.)

As in the charge proper, the subject of shou 授 is Di whose action was uncontrollable to the Shang. (For more on the controllable and uncontrollable distinction see n. 12; also T 2020). Here, it is odd to take 授 as an attempt verb because it involves no effort to accomplish the act. One either "grants" or "does not grant". 
丙辰卜䌾貞: 我弗其受㯟年.

[83B]: Crack-making on bingchen (day 53), Nan divined: "We might not (be able to) receive (= harvest) a (good) millet crop."

We agree with K's interpretation that there was a distinction between a "weaker" vs. "stronger" charge (K 1992), but here on p. 59, and on pp. 105-106, he interprets qi not as indicating a "weaker charge" but "as deictic rather than modal ... with the understanding that the 'in this case' was anaphoric, a backreference to the harvest divined in the zhengwen [positive charge], [83A]." This is a confusion of deixis and anaphora. Deixis, derived from the Greek deiktikos meaning "able to point out, indicate", is used to introduce an idea, concept, thing, person, etc. often for the first time, thus providing new information, whereas anaphora, from the Greek anapherein meaning "bringing, carrying back", is used to refer to a word or expression already introduced. If some pronoun is used instead, anaphora by its own nature refers to an antecedent whose information is old and thus shared by the hearer or reader. If we assume that K's interpretation of $q i$ as “in this case" referring to "the harvest divined in the zhengwen, [83A] (... 我受黍年)" is correct, it points to 㯟年. Since [83B] reads “... 我弗其受㯟年, one wonders why 㯟年 is repeated without using a demonstrative/pronominal zhi 之 'that, it, these; him, her, them'. There are many examples of such a usage in OBI. To give just one clear example, we find in HJ 64610 (= Bingbian 276) the following pair of charges:

辛卯卜賓貞: 沚戛啟巴; 王勿隹之从.

Crack making on xinmao (day 28), Bin divined: When Zhi Jia makes the initial assault against the $\mathrm{Ba}$, it should not be him that His Majesty follows.

辛卯卜賓貞: 沚戛啟巴; 王衣之从.

Crack making on xinmao (day 28), Bin divined: When Zhi Jia makes the initial assault against the Ba, it should be him that His Majesty follows.

The above pair shows that 之 refers to Zhi Jia 沚戛 who was already introduced before the charge was made. In the case of 秘年, however, the Shang did not use 之 (whose deictic feature is here irrelevant). Why did the Shang not use it? Perhaps we need to allow for such a case as a noun (phrase) bearing old (shared) information that could occur in succession, but not necessarily resorting to the use of a pronoun. In English we have, e.g.: "The voice of the Lord is powerful; the voice of the Lord is full of majesty. The voice of the Lord breaketh the cedars." So by repeating 㯟年 in $\left[8{ }_{3} \mathrm{~B}\right]$ the Shang may have wanted to emphasize it or, at least, to give some "prominence" to 秋年 'millet harvest'.

$Q i$ in the Neg $+q i+V$ structure functions as an adverb whose semantic properties include manner, extent/degree (inclusive, exclusive, relative), place (locative), time (temporal), quality, quantity, and protasis (conditional). But if $q i$ refers to 㯟年, it would be grammatically an "accusative" case, which does not seem classifiable to any kind of adverb in terms of semantic properties.

The syntactic position of $y i$ 亦 'also' is comparable to $q i$ before the verb and, if a negative is present, after the negative and before the verb. This supports the assignment of $q i$ to the same word class. We classify $y i$ as an extent/degree adverb as it comes under the general scope of "inclusion". Qi may also be taken as an adverb of extent/degree, because it weakens or strengthens the level of modality. ${ }^{12}$ Our general

12 We often find those cases of qi having a weakening effect in the charge, but usually (only?) when the verb is uncontrol- 
characterizations of $q i$ are modal and aspectual. The major problem we see in K assigning an anaphoric reference to $q i$, which we do not deny in toto, is that given such a syntactic analysis of $q i$ and $y i$, especially in the "Negative $+q i / y i+\mathrm{V}$ " structure, reference is hardly needed..$^{13}$ Why in this particular syntactic order can we accept K's " $q i$ as deictic rather than modal ... with the understanding that the 'in this case' was anaphoric, a back-reference to the harvest divined in the zhengwen, [83A]"? The words in question are used as part of a verb phrase (functioning as predicate). If, on the other hand, qi occurs outside the Neg $+\mathrm{V}$ nexus, as in $q i+\mathrm{Neg}+\mathrm{V}$, then $q i$ may be taken as having a referential function. A simple example out of many is cited below for illustration:

王占曰: 吉. 卋出呼. 已其伐. 其弗伐, 不吉. 'His Majesty, having prognosticated, declared: It should be that (we) indeed issue a call. On a ji day (he) will be launching an attack (against an enemy). If (he) does not attack, it will be inauspicious.'

$$
\text { HJ 6462r (= Bingbian } 277 \text { [4]) }
$$

lable. If used with a controllable verb, however, it has a strengthening effect (originally suggested by Nivison 1968). By contrast, we find those cases of $q i$ in the prognostications with a strengthening effect seemingly regardless of the assignment of controllability to a verb. For example:

(1) 王占曰: 吉. 其令. 'His Majesty, having prognosticated, declared: “It [referring to the charge made on the obverse side whether the Shang should be ordering Ju 豦 to return to the capital] is auspicious. (We) should be ordering"' HJ 419r (= Bingbian 329.7)

(2) 戊午卜賓貞: 呼取牛百, 以.王占[曰]: 吉. 以, 其至. Crack making on wuwu (day 55), Bin divined: (We) should issue a call to fetch (or gather 聚) cattle numbering one hundred, (for the one who gets called upon) will bring them along. His Majesty, having prognosticated, [declared]: "It is auspicious. (He) will bring them along; he will be going to arrive (here)." HJ 93r (= Bingbian 399.1)

In (1) the verb 令 'order' is a controllable verb as the assumed subject "we" (or "I") is a human subject with the [+will] feature. Qi preceding it should thus have a strengthening effect. In (2) 至 'reach, arrive' was to the king, the speaker, uncontrollable. It might not be impossible to interpret $q i$ here has a weakening effect, meaning "might perchance be arriving (here)". But that does not go very well with what precedes ("It is auspicious. (He) will bring them along"). Also, when qi and $y i$ 亦 are used together, the order is $q i$ invariably occurring before $y i$; e.g., 今夕其亦雨 'it might be going to rain this evening again'一 it seems that the nature of the "adverb of extent/degree" we have assigned to both qi and $y i$ has a difference in that $q i$ is modal, while $y i$ in and of itself is not (though if $y i$ as an extent/degree adverb can be taken as "extensive inclusion", it can become modal as in 不亦樂乎), a rhetorical question in Classical Chinese (abbreviated hereinafter as CC).

Incidentally, we have been testing the validity of such a distinction for quite some time and have come to think that the distinction reveals the Shang people's Weltanschauung such that what was humanly controllable was sharply distinguished from what was not.

13 We have mentioned that $q i$ in the "Neg+qi+V" structure is the result of a historical process known as lexicalization, whereby its original grammatical function of pronominal-genitive generates various semantic overtones. How the process unfolded is a question no one seems to have pursued. How to go about analyzing the process is not even clear. Perhaps one way to approach the question is, first, to find as many examples of the so-called "cliticized expressions". In OBI we find "negative clitics” such as, e.g., 余不爾其合 'I will not be joining you' (HJ 32970), 帝不我其授祐 'Di might not be granting us divine succor' (HJ 65050), 靠勿余害 'Numen (of this bone), don't harm me' (HJ 8090), 師不余其見 'The army officer might not be having an audience with me' (HJ 20391), 龜不其豕以 'Gui might not be bringing his pigs' (Tōbunken 311), etc. This sort of negative-clitic structure obtains when the verb is transitive and its object-be it either indirect as in the first four examples or direct as in the last one-is fronted out of the normal SVO order. So, in the qi-bearing negative-clitic structure it seems reasonable to think that qi still retains its pronominal function. Now compare these examples with the standard word order Neg $+q i+\mathrm{V}$ as in 我弗其受㯟年 'We might not (be able to) harvest a (good) crop of millet'一 [83B], 弗其以武忽 '(They [someone not under the control of the diviner]) will not (be able to) bring Wǔ's soldiers/foragers'HJ 456o, 王弗其疾目 'His Majesty might not ail (in his) eyes'- HJ 456o. It is hard to see any pronominal function of $q i$ in this structure, let alone genitive feature. Thus, the process of lexicalization was closely linked with these syntactic constraints. 
N.B. This prognostication goes with the following charge on the obverse side: 呼从爱肯 [+another 矢 under 止] '(We) should issue a call to follow Yuan Jian (箭?).'

Whoever gets called upon (issued a call) presumably by the Shang court after the prognostication (verdict) by the king, he was proposed to launch an attack against an enemy. ${ }^{14}$ In the above example, 其 is placed before Neg $+\mathrm{V}$. Thus, 其 is no longer adverbial, but pronominal, substituting the proper noun Yuan Jian. Moreover, since 其 is genitive according to our interpretation, 其弗伐 constitutes a noun phrase literally meaning "his not attacking". If this is taken as a topic, we can put "As for his not attacking, it will not be inauspicious." Since topic often serves pragmatically as a conditional clause, we have suggested to translate 其弗伐, 不吉 as provided above.

Another problem with K's rendition of $q i$ "in this case" is that, as already mentioned, we cannot pin down what that "this" refers to. His translation suggests that the qi phrase is construed as subordinate (conditional), but if applied to $\left[8_{3} \mathrm{~B}\right]$, it yields something like "In this case, we will not receive a millet harvest." We do not want to end up with a sentence as illogical as "*In the event of wo shou shu nian 我 受秋年, we will not receive a millet harvest." Similarly, "in this case” generates nothing but confusion if applied to such cases as, e.g., bu yu-which we translate "It will not happen to rain", "It will not be raining", or even "It is not about to rain" (this only when we find contextual support) —followed by a separate charge, qi yu, which K has translated: "It will in this case rain" (= "In this case, it will rain."). Now reflect this on the Li-group inscriptions in $\mathrm{HJ} 33807$ (not cited by K) where qi yu occurs before bu yu; we can hardly interpret qiyu as "*In the case of buyu, it will rain" because qi as referring to a separate entity, here $y u$ 'rain', but this is negated, forming an integral unit. Therefore, if qi yu occurs before bu $y u$ as it does in HJ 33807 , qi has to refer to the integral unit.

K does qualify his interpretation ${ }^{15}$ by invoking what he calls "inter-charge reference" (p. 108, n. 206), a reference in one charge to a topic in another, as opposed to "intra-charge reference", a reference from one part of a charge to a topic in another part of the same charge ${ }^{16}$ If we accept this, qi presumably refers to nian 年 'harvest', a noun. If this is inserted in the 我弗其受㯟年 syntax, i.e., $\mathrm{N}_{1}+\mathrm{Neg}+q i+$ $\mathrm{V}+\mathrm{N}_{2}$, we obtain ${ }^{*} \mathrm{~N}_{1}+\mathrm{Neg}+\operatorname{ProN}+\mathrm{V}+\mathrm{N}_{2}$. This syntax is difficult to comprehend, since not only is the ProN-abbreviation of ProNominal (= pronominal; abbreviation of "Pron" is generally taken as "pronoun" or "pronominal" which we wanted to avoid) specially made to cover K's "inter-charge reference" and "intra-charge reference" — supposed to be anaphoric of nian, but also identical to the $\mathrm{N}_{2}$ within the same sentence. It strikes us as bizarre.

Let us now consider:

p. 60 [84A]: 辛亥貞:受禾.

Divined on xinhai (day 48): “(We) will harvest grain.”

[81B]: 不受禾.

"(We) will not happen to harvest grain."

Neither the positive nor the negative member of the above pair has any overt marker of modality, but the use of the negative $b u$ (in contrast to $f u$ ) indicates that in terms of aspect it is eventive/stative, rather

\footnotetext{
14 Here "launch an attack" 伐 seems to have been marked as an "attempt", not a "success" verb.

15 To quote once again: “... the 'in this case' was anaphoric, a back-reference to the harvest divined in the zhengwen, [83A]."

16 Personal communication dated August 9, 1995 (four days before T 1995 was written).
} 
than dynamic/mutative (as $f u$ is). The translation we suggest for such an expression is "not happen to + V"; "is not going to + V", or even "is not about to". This is intended to convey its eventive aspect. The translation, however, is somewhat awkward, but since English does not incorporate aspectual meanings in its grammar as it does, e.g., in Japanese (like ame ga furisō dewa nai 雨が降りそうではない; ame ga furu yō dewa nai 雨が降るようではない) one would have to use more "lexical" and idiomatic expressions like "not happen to", "not going to", or "be not about to". In a sense, this is a form of aspectual expression in English.

On p. $61 \mathrm{~K}$ translates shou you you 受出又 as “(We) will receive assistance in this case.” We see no distinction between $q i$ 其 and you 出, both of which have been rendered "in this case". The authority K relies on is Nivison (1977), which seems to us a classic case of confusing reference and existence (cf. rejoinder, T 1978; surrejoinder, Nivison 1978; surrejoinder, T 1980). Shou you you is quite different from *shou qi you - which, unfortunately for the position taken by Nivison and K, does not occur, but does imply, conversely, that a clear distinction has to be made between nominal/pronominal reference and verbal existence (existential verb). It does not permit the substitution of you for $q i$, and vice versa because the two words are grammatically entirely different. To be sure, K does distinguish qi and you by attributing "inter-charge reference" to the former and "intra-charge reference" to the latter (cf. p. 108, n. 206). But, as already mentioned, you 'there is, have' can never be a pronoun in and of itself and thus has neither an intrinsic, nor even an extended, referential function. Moreover, as in examples [6oA] and [6oB] cited below, qi should be considered a resumptive and genitive pronoun, which nominalizes the following verb. We address this point below.

p. 62 Here, discussing examples [6oB, C; given below], K suggests a "quasi-wei" construction. We think there is no such a thing. Instead, the interpretation $\mathrm{K}$ has rejected is what we deem correct. Our suggested translations for the examples in question are as follows:

p. 47 [6oA]: 已未貞: 王其告其比亞侯.

On jiwei (day 56) divined: "The king, his making ritual-reporting his following Ya Hou."

Strictly speaking, the translation, a literal one, is not a complete sentence. Pragmatically, it may be rendered as: "The king should be going to perform the announcement ritual (that he) follow Ya Hou."17 Perhaps somewhat more smoothly: "The king should announce his (intention to) follow Ya Hou" (cf. T 1994: 14). There are about 40 additional, related examples K provides accompanied with his descriptiveanalytical comments; we cite here only four with our translations.

[6oB]: 庚申貞: 王其告于大示.

On gengshen (day 57) divined: "The king should be performing the announcement ritual to the Great Ancestors."

[6oC]: 庚申貞: 王于父丁告.

On gengshen (day 57) divined: "The king should perform the announcement ritual to Father Ding."

17 Note that the translation “*The king should (indeed) happen to perform the announcement ritual (that he) follow Ya Hou" does not work because gao 告 'to make a ritual announcement' is a controllable verb. 
[61]: Ø貞: 來 [乙]亥告自上甲.

On ... divined: "On the coming [yi-]hai (day 12), (The king should) perform the announcement ritual starting from Shang Jia (on down).”

[62]: 丁已貞: 其告自上甲.

Divined on dingsi (day 54): "(The king) should be performing the announcement ritual starting from Shang Jia (on down)."

On p. 62, K gives what we think as correct understanding of the nature of deixis: "I have observed ... that in unpaired Li-group charges, the $q i$ was more likely to be present when the charge was the first one on that particular topic divined on that particular day ..., thus emphasizing the sense of will 'in this case, now'” (Italics for emphasis ours.) But then, on p. 63, he states “... this tendency was directly opposed to the preference of the Bin-group diviners for inserting qi in what was often the second charge of a chargepair." (Ditto above.) Given the fact that the Li-group and Bin-group are roughly co-eval, it seems rather strange that their language differed so significantly as to make the use of $q i$ almost opposite. Also, the former quote seems to undermine K's theory of $q i$, for it is tantamount to denying the anaphoric function he has assigned to it. ${ }^{18}$

K tries to avoid the kind of difficulty mentioned in the previous paragraph by conjuring up a "quasi-wei construction", claimed applicable to [6oA, B], [61], and [62] we have just translated. In these examples, there is no use of wei 隹 anywhere. It is therefore difficult to find any basis for the existence of such a construction. In [6oA] (已未貞: 王其告其从亞侯), what follows the verb gao 告 “to make a ritual-report, perform an announcement ritual" is a direct-object clause. This example is interesting as there are two tokens of $q i{ }^{19}$ and the second one suggests that it is resumptive of wang 王 'king' in what we also find as a standard grammatical construction in CC. It is clear that $q i$ is also genitive literally meaning "his following Ya Hou". In [6oB], what follows the same verb is an indirect object introduced by the locative particle $y u$ 于 'to, in, from, by (only in the passive construction)' as it is in [6oC], [63], [64], [65], [67], [68], and so on. In [61] and [62] we find the use of $z i$ 自 'to start from' — a word not as "grammaticalized" as 于 was in Shang Chinese-occupying the same syntactic position as 于, but we think it functions as an adverbial complement ( $\mathrm{T}$ 1985) rather than a simple indirect-object phrase. In short, $\mathrm{K}$ seems to have ended up with a surreal hypothesis of a "quasi-wei construction".

We have reiterated that $q i$ in $[6 \circ \mathrm{A}]$ and $[6 \circ \mathrm{B}]$ functions as a pronoun in its genitive case (e.g., T 1994; 2010: 24; 2020: 311), and the exact referend (antecedent) has to be determined contextually. The simplest one, frequently occurring immediately before $q i$, is a noun like 王 as in [6oA, B; a plethora of others], a

18 Cf. our discussion on the $\mathrm{HJ} 33807$ inscriptions (several paragraphs before this).

19 In $\mathrm{n} .23$ on p. 11, K. has raised the possibility that the first use of $q i$ "might have served to delimit a past event". The inscrip-

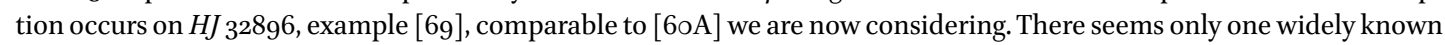
case of $q i$ used in verification accepted by a few scholars, and that occurs in HJ 13399f: 庚子酸; 三嗇 [色] 雲笯; 其既祝, 啟. 'On gengzi (day 37) we conducted the you-cutting sacrifice; three colored clouds RUK (read "reading unknown”, but must have stood for a verb); when we completed our prayer offering, it became clear'. If $\mathrm{K}$ is correct in his interpretation of [69] and [6oA], they can be counted as additional examples. However, we are now entertaining an alternative interpretation. Another important point about the $H J 13399 \mathrm{f}$ inscription just quoted is that 其 can only be taken as pronominal genitive, literally meaning “(our) having completed the prayer offering, it became clear." Functionally, the phrase “其既祝” plays the role of a topic, and since the topic often forms a subordinate clause, it may be rendered: "When we completed our prayer offering, it became clear." (For yet another, perhaps more credible, example of 其 used in the verification, is: ... 子其又(有)疾。允其又(有)。'Zi might be suffering from illness. Indeed, he was.') - HYZ 331.1. 
proper noun like E 娥 (e.g., [125A]), Bing 並 (e.g.,... 並其域眾人 'Bing might be losing the royal retinue and men'-HJ 51), as well as a pronoun like wo 我 (e.g., ... 我其喪眾人 'We might be losing the royal retinue and men'-HJ 500), $y u$ 余 (e.g., 余其作邑 'I will be founding a settlement'- HJ13503). Another very common referend is zero on the surface, but it is most likely wo 我 'we' as can be inferred from [64]-[68], [125A], $[129 \mathrm{~A}, \mathrm{~B}],[13 \mathrm{O}]-[132 \mathrm{~B}]$, etc. When a verb follows after any one of these referends, it gets nominalized by $q i$ because it is genitive. In $[6 \circ \mathrm{A}]$ and $[6 \circ \mathrm{B}]$ the verbs are gao 告 and cong 从 'follow'. ${ }^{20}$ If nominalized, they are, strictly speaking, no longer verbs and become a kind of quasi-verb phrase or, better, noun phrase. As a result, various modal meanings would be generated such as "emphasis", "resoluteness" (determination), "exclamation", "surprise", "disbelief", "question", and so forth, the choice depending upon the kind of verb (controllable or uncontrollable, stative/eventive or dynamic, of success or attempt, taking context into consideration). Of course, the problem lies in figuring out what the Shang speakers or writers originally intended. If we judge that "emphasis", for instance, is appropriate, then we can add words like "indeed", "surely", "in fact", and the like. There is also the problem of absence of truly objective criteria to decide which might have been what the Shang intended to say. This is the fundamental problem of the nature of modality, and we cannot solve it to everyone's satisfaction. We only aim at arriving at a general consensus.

Our interpretation is also based on the assumed existence of a certain specific presupposition on the part of the speaker before the utterance was made. Frequently the presupposition is not apparent, but when detectable, there are a few ways in which it surfaces. One way, we think, is the use of $q i$. Its meaning is highly modal when followed by a verb. In fact, it may well be the origin of the modal particle $q i$ in CC. ${ }^{21}$

To recapitulate, [6oA] may be translated literally as: "The king, his making ritual-reporting his following Ya Hou", wherein "his following Ya Hou" is the direct object (content) of gao "to make a ritual-reporting of ...". At the same time, $q i$ is prospective, implying a sense of imminence. Thus, "be going to" or "be about to"-the latter, if used with a time word/phrase of a shorter duration like "in a moment", "right now", "soon", etc., seems appropriate, but with a time word/phrase of a longer duration like "tomorrow", "next week", "in a month", etc., seems inappropriate — can be superimposed on the modal meaning (and vice versa). In addition to "be going to", which is applicable to both controllable and uncontrollable verbs, we can think of "happen to", but this prospective meaning seems applicable mainly to uncontrollable verbs. The absence of $q i$ in [6oC] and [61] simply means that the diviner did not add these modal and aspectual meanings. After all, they were not grammatically required. This sort of explanation seems capable of accounting for these examples better than what we think of as a spurious "quasi-wei construction", along with the complicated rules of divination, "divinatory conventions", $\mathrm{K}$ is appealing to.

20 What we have taken as cong 从 is interpreted by $\mathrm{K}$ and almost everyone else as bi 比 'join with (< lit. compare with)', but we have reservations. Contextually considered, sometimes the "join with" meaning does seem to make sense. The problem

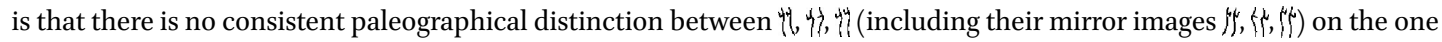

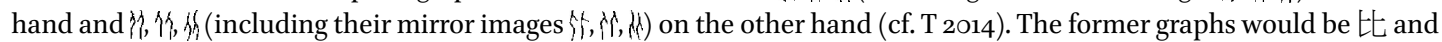
the latter 从. Thus, we must rely entirely on context, and yet the meanings of "follow" (e.g., A follows B) and "join with" (e.g., A joins with B) are not disparate enough to allow the optimum choice. We have come to think this way after further rumination on $\mathrm{T}$ (2014).

21 I have reflected on this hypothesis for about a quarter of a century, testing its validity against the pertinent examples at every opportunity. Some finer modifications were required for it since the initial formulation in 1994, but by and large it seems to work quite well. A problem is that I have not found other scholars' works that offer counter interpretations. There are several related works, but they are done in a piecemeal fashion without accounting for the interrelated grammatical and semantic issues involved (e.g., Shen Pei 2005). T (2020) is an updated version of the interpretation. 
p. 48 [63]: 已巳貞: 告于口牛一.

Crack-making on jisi (day 6): "Perform the announcement ritual to Ancestor Ding (K's reading: the sun) with bovine amounting one."

[64]: 癸西卜:其告于口牛一.

Crack-making on guiyou (day 10): "(The king) should be going to perform the announcement ritual to Ancestor Ding (K's reading: the sun) with bovine amounting to one."

[65]: 癸西卜:其告于父乙一牛.

On guiyou (day 10): "(The king) should be going to perform the announcement ritual to Father Yi with one bovine."22

[67]: 辛巳卜: 其告水入于上甲, 祝大乙牛.

Crack-making on xinsi (day 18): "(The king) should be going to ritually announce the entry of the floods to Shang Jia, and offer prayer to Da Yi with one bovine."

K's translation for [67] poses some problems. $Q i$ is not used in front of the verb $z h u$ 祝 'offer prayer, make invocation', and yet the sentence is translated “... the entry of floods to Shang Jia, in this case make invocation to ..." as if it were there. If this was merely a lapse, a minor correction would do; but it appears to be more than that because $\mathrm{K}$ appeals to a convention that the Li-group diviners placed $q i$ at the head of complex ritual-report charges. Does the scope of qi extend to the second verb zhu? That might not be impossible, but $\mathrm{K}$ is also taking qi gao as the dependent and $z h u$ as main clause. At first sight, this does seem problematical, but to make sure that it is not a premature judgment we further examine it and related issues below.

According to Chow Kwok-ching (1983), the verb gao in [63]-[67], is a Type-A ritual-sacrificial (Chow abbreviated this as "R-S", a misnomer), "four-place" verb, requiring on the underlying level an agent (subject), a patient (direct object), a beneficiary (indirect object), and an instrumental object. There are actually not many examples that come with all these grammatical elements intact, but they do not affect the validity of such an analytical model. K has adopted Chow's model including the term "R-S", but has applied it incorrectly to some examples. Chow would have read sentences like [63] and [67] to be not complex, as K did by supplying an assumed verb "offer" for the former (K's translation of [63] reads: "In making ritual-report to the sun, (offer) one bovid") and by translating qi gao in [67] as "in rituallyreporting". [63]-[66] are all simple sentences, and [67] a compound sentence.

K has translated [9oC] (辛未貞: 其禱禾于高祖) as “The praying for grain (will be) to the High Ancestors", but there is no basis for supplying "will be". We think [9oC] should be translated "(We) will be going to pray for (a good crop of) grain to the High Ancestors." But he is correct in interpreting examples [9oD, F, and G] (e.g., [9oD] reads: 辛未貞: 禱禾于高祖, 燎五十牛) as complex sentences because they contain Type-B sacrificial verbs such as liao 燎 'perform burnt offering', you 酸 'to conduct a cutting sacrifice'

22 There is a difference in meaning between 牛一 in $[63,64]$ and 一牛 in [65]. In the former一with the numeral 一 occurring after a noun (here 牛) it is the noun that provides new information, while in the latter-with the noun 牛 occurring after the numeral, it is the numeral that provides new information. 
[9oF], and chen 沈 'to conduct a drowning sacrifice' [9oG]. When these Type-B sacrificial verbs accompany the Type-A ritual verbs, they function as if they were instrumental nouns. In Shang Chinese an instrumental noun is specified as a valent without any marker - all that is required is that main verb can be categorized as Type A. In CC, however, the Type-A and Type-B distinction of a verb is lost, and the instrumental noun is introduced by the so-called "co-verb" $y i$ 以 'by means of, with the use of'. We thus make a distinction between "sacrificial" and "ritual" verbs. If we use "R-S verbs", the distinction is lost (T 2002).

p. 98 [125A]: 娥其害我.

"E might be harming the king." R (= Right side of plastron, abbreviated as R hereunder)

[125B]: 貞: 娥弗害王.

Divined: "E will not harm the king." L (= Left side of the plastron, abbreviated as L hereunder)

[126A]: 貞: 娥害王.

Divined: "E will harm the king." R

[126B]: 娥弗害王.

"E will not harm the king." L

First, there is a general rule of the Shang scribe inscribing the desirable charges on the right-hand, and the undesirable charges on the left-hand, side of a plastron. However, the rule does not apply to the above two charge pairs. There are exceptions like these (cf. Shen Pei [2005] who has collected more exceptions), and they are thus irregular for reasons we have not been able to work out. Second, according to our grammatically motivated analysis, $[125 \mathrm{~A}]$ should be translated as given. By contrast, K's translation reads: "E is not in this case harming the king." We have already discussed problems in translating $q i$ as "in this case". In addition to a series of simple charge pairs in $H J 33807$ (n. 18), the [125A] and [125B] charge pair should also be counted as yet another example of ambiguous reference made by "in this case". We are not sure of exactly what "this" really refers to and, if the referent is not clear, there is no raison d'être of the demonstrative "this" itself.

Both [126A] and [126B] are not marked either aspectually or modally (no $q i$ ). They have an "equalinformation value", except of course the presence or absence of a negative, here $f u$ 弗. They are semantically "balanced" charges much like an interrogative sentence “ni qu bu qu 你去不去?" in modern Chinese (去 and 不去 are free of aspect and modality). So, when the positive and the negative charges are taken together, they generate a question. However, not all that many balanced charges are found in the OBI corpus when compared with those with an "unequal, biased-information" value. The latter is closely related to the notion of presupposition.

We have already discussed the problem of taking qi as meaning "in this case", an original idea of David Nivison $(1977,1978)$, further elaborated by K in the present article we have been re-examining. A review of $H J 1677 \mathrm{f}$ and $738 \mathrm{f}$ indicates that the overall context in which [125A] (= HJ $1677 \mathrm{f}$ ) occurs is quite different from that of [126A] on $\mathrm{HJ} 738 \mathrm{f}$. Since the date and the subject matter of divination were in general interrelated, the use of $q i$ is consistent with that used in $[6 \circ \mathrm{A}]$ and $[6 \circ \mathrm{B}]$, examples of the Li-group inscriptions. 
The syntactic position it occupies is after the subject $\mathrm{E}$, a proper noun, and before the verb hai 害 in [125A]. So in $[6 \circ \mathrm{A}]$, [6oB] , and $[125 \mathrm{~A}]$ we get the pattern: $\mathrm{S} / \mathrm{Top}+q i+\mathrm{V}(\mathrm{P}) \cdot{ }^{23}$ Our analysis of this pattern has been for quite some time to take $q i$ as a resumptive pronoun even when a $\mathrm{S} / \mathrm{Top}$ immediately precedes it, for which a plethora of examples in OBI, bronze inscriptions, and CC can be adduced. Moreover, qi in that pattern is not the nominal but genitive (possessive) case, as it is even in modern Chinese (more often in written language). If we apply this analysis to $q i+\mathrm{V}(\mathrm{P})$, the $\mathrm{V}(\mathrm{P})$ gets nominalized. Even though there is no real $\mathrm{V}(\mathrm{P})$, pragmatically it can be interpreted as a legitimate utterance. We have already mentioned all these, but further elaborated on them elsewhere (e.g., most recently in T 2020: 311-312).

The illocutionary force of such a syntactically incomplete string produces various semantic effects such as exclamation (wonder, amazement, disbelief), interrogation (question, rhetorical question), and affirmation (confirmation, agreement), all of which are modal overtones. Since [125A] occurs on the desirable right side of the plastron (a general trend), the effect is not to stress that the spirit $\mathrm{E}$ is going to harm the king. We suggest that $q i$ is a lexical realization of such a presupposition as E's harming the king was to be averted. The answer to the unspoken (but underlying) question "Will E harm the king?" in the Shang diviner's mind may well have been "No, E will not happen to harm him," a message sent to the spirit. If all these translations were framed in the future progressive aspect (be + V-ing, "be harming"), they would be incorrect because the negative used in $[125 \mathrm{~B}]$ and $[126 \mathrm{~B}]$ is $f u$ 弗, not $b u$ 不. We therefore take issue with K's translation of $[125 \mathrm{~B}]$ framed in the progressive aspect: " $\mathrm{E}$ is harming the king." The salient feature of the negative $f u$ 弗 must be taken into account, and since it is best taken, in our view, as a dynamic and mutative negative - sc. rusheng *-t coda in OC as opposed to an "undynamic" or "stative/eventive" one with no coda in OC-negating uncontrollable verbs, it cannot be translated as "E is harming the king." Thus, fu hai must have meant "(some spirit) will not harm ...," where hai 'harm', an action and process verb, is semantically an uncontrollable, grammatically a mutative/dynamic, verb.

p. 99 [127A]: 王午卜䌾貞:王出夢; 其出禍.

Crack-making on renwu (day 19), Que [> Nan] divined: "The king had a dream; there might be going to be something ominous." $\mathrm{R}$

[127B]: \卜䌾 $\square$ :王出夢; 亡禍.

Crack-making on [renwu] (day 19), Que [> Nan] [divined]: "The king had a dream; there shall be nothing ominous." L

Khas argued that qi in $[127 \mathrm{~A}]$ is required in this complex — should be compound — charge because it "provided a resumptive agent [read "experiencer"] for the you 出; [h] ad the closing clause been wei huo 隹禍 rather than you huo 出禍, the qi would have been unnecessary." ${ }^{44}$ But since qi wei huo 其隹禍 does occur as in $H J 32010,7152$ r, 16445, 17461, 40422, etc., the fact that $q i$ is not used in [127 B] must be explained in a different way. First, [127A] is a "weak" charge, giving the benefit of the doubt for the possible realization of the unwanted 出禍 and, at the same time, hoping the numen of the turtle to respond positively. Second, you and wang are expected to have the same grammatical properties, except, of course, you is positive

\footnotetext{
23 Since $q i$ is not used in $\left[125^{\mathrm{B}}\right]$ evidently because the diviner did not want to "weaken" this charge, [125B] does not count. The graph $\mathrm{K}$ transcribes as hai is our sui 崇, but this is immaterial to the present discussion. Both have adverse meanings.

$24 \mathrm{~K}$ takes the graph $\mathrm{\text {a }}$ huo 禍 'misfortune, something ominous', while many contemporary scholars take it as you 憂 'worry, anxiety'. K's rendition follows the older, traditional, interpretation which, we think, is supported by paleographical evolution, as well as by context (see, e.g., $H J$ 40422), better than the new interpretation.
} 
and wang negative. ${ }^{25}$ The reason why $q i$ is not used in $[127 \mathrm{~B}]$ is that since it is a manifestation of what the diviner, here Nan, decided before he uttered this charge that, we have 亡禍 'not have anything ominous', which must surely have been sought-after. The expression may well be taken as apotropaic, characteristic of the OBI of later periods (Period III-IV and V), but since [127A] and [127 B] belong to the Model Bingroup (Period I-II), the divination, accompanied by utterance, was done on the basis of a belief in the power of cracks to avert evil influence, as well as to usher in good influence (T 1989: 15-22).

Another problem is that although $\mathrm{K}$ has correctly taken qi to be possessive, as indeed required for his "demotion" theory (see his paper, p. 6). What was ominous is not to be ascribed to a person himself, but a person who had experienced something - which in the case of $[127 \mathrm{~A}]$ and $[127 \mathrm{~B}]$ was that the king had a nightmare.

We would maintain that the $q i$ in $[127 \mathrm{~A}]$ functions the same as it does in [125A]. It is modally and aspectually marked. Also, given that it occurs on the desirable-right rule of thumb, it matches with the diviner's presupposition that "the king's having experienced something ominous" was undesirable. When we factor in the aspectual modification of imminently prospective "be going to", we arrive at the translation suggested above. Qi you huo can be rendered in a different way, for instance, "something ominous/unpropitious might (soon) be happening to the king." Here Serruys' rule of "undesirable qi" works, not "accidentally" as Nivison (1992) has it, but because the modality of $q i$ is towards the "wish" side of the "intention/wish" scale. $Q i$ is a manifestation of the Shang diviners' (including their "employers'”) wishes superimposed on the uncontrollable happening huo.

There still remains much more rigorous testing before our hypotheses concerning $q i$ can be elevated to the status of an integrated theory, but on the whole we are more attracted to our comparatively autonomous interpretation of qi than to K's version, which seems less autonomous, dependent on this and that, here "inter-charge reference", there "intra-charge reference", you 出 having a referential function like $q i$ 其, the imaginary “quasi-wei 隹” construction, and so on. Faced with the necessities as required by synchronic and diachronic analyses of $q i$ and words relevant to it, we should try not to make things too complicated, seemingly inordinately interdependent on various provisos.

\section{Abbreviations}

HJ Heji 合集. Guo, Moruo 郭沫若 (ed.) and Hu Houxuan 胡厚宣 (editor-in-chief). 1978-1982. Jiaguwen heji 甲骨文合集, 13 vols. Beijing: Zhonghua shiju 中華書局,

HJSW Heji shiwen 合集釋文. Hu Houxuan 胡厚宣 (editor-in-chief). Associate editors: Wang Yuxin 王 宇信, Yang Shengnan 楊升南, Meng Shikai 孟世凱, Xie Ji 謝濟. 1999. Jiaguwen heji shiwen 甲骨 文合集釋文, 4 vols. Beijing: Zhonghua shiju 中華書局.

HYZ Huayuanzhuang 花園莊. Institute of Archaeology, Chinese Academy of Social Sciences. Yinxu Huayuanzhuang dongdi jiagu 殷噓花園莊東地甲骨, 6 vols. Kunming: Yunnan renmin chubanshe 雲南人民出版社, 2003.

Jiabian Jiabian 甲編. Dong Zuobin 董作賓. 1948. Xiaotun dierben: Yinxu wenzi: Jiabian 小屯第二本一 殷噓文字一甲編. Nanjing: The Commercial Press. Reprinted in Taipei: Institute of History and Philology, Academia Sinica, 1977.

25 The reading of the graph 亡 may well have been different in OC and possibly also in pre-OC. We suspect there was in Shang Chinese a morphological difference between wang/*man 亡 and $w u /{ }^{*} \mathrm{ma}$ 亡 (later written as 無). For further details, the reader is referred to $\mathrm{T}(2 \mathrm{O} 20: 287, \mathrm{n} .4)$. 


\section{References}

Chow Kwok-ching 周國正. 1983. Buci liangzhong jisi dongci de yufa tezheng ji youguan juzi de yufa fenxi 卜辭両種 祭祀動詞的語法特徵及有關句子的語法分析, Guwenzixue lunji 古文字學論集—Chubian 初編, 226-307. Hong Kong: Research Institute of Chinese Culture, Chinese University of Hong Kong.

Fu Sinian 傅斯年. 1935. Yi Xia dongxi shuo 夷夏東西說. Qingzhu Cai Yuanpei xiansheng liushiwusui lunwenji 慶祝蔡 元培先生六十五歲論文集, Vol. 2, 1093-1134. Taipei: Institute of History and Philology, Academia Sinica.

Itō, Michiharu 伊藤道治 and Takashima Ken-ichi 高嶋謙一. 1996. Studies in Early Chinese Civilization: Religion, Society, Language and Palaeography, 2 Vols. Hirakata 枚方: Kansai Gaidai University Press 關西外大出版社. Part I: Religion and Society (pp. 1-178, Vol. 1) is by Itō, and Part II: Language and Palaeography (pp. 179-505, Vol. 1) is by Takashima. Downloadable from: https://www.academia.edu/30723970/Takashima_Ito_Studies_in _Early_Chinese_Civilization

Keightley, David N. 1978. Sources of Shang History: The Oracle-Bone Inscriptions of Bronze Age China. Berkeley: University of California Press.

Keightley, David N. 1992. Shang Charges and Prognostications: The Strong and the Weak? The 25th International Conference on Sino-Tibetan Linguistics. Berkeley. 15 October 1992. Typescript ms.

Keightley, David N. 1994. Executive Qi in the Shang Oracle-Bone Inscriptions: A New Hypothesis. Typescript ms. dated 30 January, 1994, original paper of another article in the present volume.

Keightley, David N. 1995. Divinatory Conventions and Grammar in the Shang Oracular Inscriptions: Notes on a Recent Contribution of Professor David N. Keightley. Unpublished ms. dated 13 August, 1995, original monographlength paper of the present article.

Mei, Tsu-lin. 1981. A Common Etymon for 之 chih and 其 ch'i and Related Problems in Old Chinese Phonology. Zhongyang yanjiuyuan guoji Hanxue huiyi lunwenji 中央研究院國際漢學會論文集: Yuyan wenzi zu 語言文字組, 185-211. Taipei: Academia Sinica.

Mei, Tsu-lin and Norman, Jerry. 1976. The Austroasiatics in Ancient South China: Some Lexical Evidence. Monumenta Serica, 32, 274-301.

Nivison, David S. 1968. So-called 'modal ch'i' in Classical Chinese. Paper presented to the Annual Meeting of the American Oriental Society. Berkeley, 19 March.

Nivison, David S. 1977. The pronominal use of the verb $y u$ (GIǓG: 出, 久, 鸟, 有) in Early Archaic Chinese. Early China, $3,1-17$.

Nivison, David S. 1978. Reply to Professor Takashima. Early China, 4, 30-36.

Nivison, David S. 1992. A new attempt on 'modal Qi': Another note on Serruys' 'Notes'. Typescript ms. January, 1992.

Nivison, David S. 1996. Response to K. Takashima, 'Towards a new pronominal hypothesis of $Q i$ in Shang Chinese'. Chinese Language, Thought, and Culture: Nivison and His Critics, ed. by Philip J. Ivanhoe, 267-277. Chicago and La Salle: Open Court.

Pulleyblank, Edwin G. 1983. The Chinese and their neighbors in prehistoric and early historic times. The Origins of Chinese Civilization, ed. by David N. Keightley, 411-466. Berkeley: University of California Press.

Pulleyblank, Edwin G. 1995. The historical and prehistorical relationships of Chinese. The Ancestry of the Chinese Language, ed. by William S-Y. Wang, 145-194. Journal of Chinese Linguistics, Monograph Series, No. 8.

Shen Pei 沈培. 2005. Yinxu buci zhengfan duizhen de yuyongxue kaocha 殷虚卜辭正反對貞的語用學考察. Essays in Chinese Historical Linguistics: Festschrift in Memory of Professor Fang-Kuei Li on His Centennial Birthday, eds. by Pang-Hsin Ting and Anne O. Yue, 191-234. Taipei: Institute of Linguistics, Academia Sinica and Seattle: University of Washington.

Takashima, Ken-ichi 高嶋謙一. 1978. Decipherment of the word $y u$ 出/ // 有 in the Shang oracle-bone inscriptions and in pre-classical Chinese. Early China, 4: 19-29. 
Takashima, Ken-ichi. 1980. The early archaic Chinese word $y u$ 出 in the Shang oracle-bone inscriptions: Word family, etymology, grammar, semantics and sacrifice. Cahiers de Linguistique Asie Orientale, 8, 81-112.

Takashima, Ken-ichi. 1985. On the quantitative complement in oracle-bone inscriptions. Journal of Chinese Linguistics, 13(1), 44-68.

Takashima, Ken-ichi. 1989. Indai teiboku gengo no honshitsu 殷代貞卜言語の本質. Tokyo daigaku tōyō bunka kenkyūsho kiyo 東京大學東洋文化研究所紀要, No. 110, pp. 1-110.

Takashima, Ken-ichi. 1994. The modal and aspectual particle Qi in Shang Chinese, Papers of the First International Congress on Pre-Qin Chinese Grammar, eds. by Robert H. Gassmann and He Leshi 何樂士, 479-565. Changsha: Yuelu shushe 岳麓書社.

Takashima, Ken-ichi. 1995. Divinatory conventions and grammar in the Shang oracular inscriptions: Notes on a recent contribution of Professor David N. Keightley. Unpublished ms. dated 13 August, 1995, original paper of the present article.

Takashima, Ken-ichi. 2002. Some ritual verbs in Shang texts. Journal of Chinese Linguistics, 30(1), 97-141.

Takashima, Ken-ichi. 2010. II. Studies of Fascicle Three of Inscriptions from the Yin Ruins, Volume II: New Palaeographical and Philological Commentaries (殷墟文字丙編研究, 下冊, 註釋·古文字語言學新探). Taipei: Institute of History and Philology, Academia Sinica. Special Publications No. 107B (專刊之一○七B).

Takashima, Ken-ichi. 2014. Two competing interpretations: Cóng 从 or Bi 比 in oracle-bone inscriptions. Studies in Chinese and Sino-Tibetan Linguistics: Dialect, Phonology, Transcription and Text, eds. by Richard VanNess Simmons and Newell Ann Van Auken, 367-377. Taipei: Institute of Linguistics, Academia Sinica.

Takashima, Ken-ichi. 2019. A Little Primer of Chinese Oracle-Bone Inscriptions with Some Exercises. 2nd Revised Edition. Wiesbaden: Harrassowitz Verlag.

Takashima, Ken-ichi. 2020. A lexical category in oracle-bone inscriptions: $\mathrm{V}_{\text {Controllable }}$ or $\mathrm{V}_{\text {Uncontrollable. }}$ In A Typological Approach to Grammaticalization and Lexicalization: East Meets West, ed. by Janet Zhiqun Xing, 283-317. Berlin: Walter de Gruyter GmbH.

Takashima, Ken-ichi 高嶋謙一 and Anne O. Yue 余靄芹. 200o. Evidence of possible dialect mixture in oracle-bone inscriptions. Memory of Professor Li Fang-Kuei: Essays of Linguistic Change and the Chinese Dialects, eds. by Ting Pang-Hsin 丁邦新 and Anne O. Yue 余䨠芹, 1-52. Taipei: Institute of Linguistics [Preparatory Office], Academia Sinica.

Yue, Anne O. 1998. Zhi 之 in pre-Qin Chinese. T'oung Pao, 84, 239-292. 


\title{
〈晚商占卜慣例〉及甲骨文語法榷略
}

\author{
高嶋謙一 \\ 英屬哥倫比亞大學, 溫哥華, 加拿大 \\ kenichi.takashima@ubc.ca
}

\section{摘要}

本文將對吉德煒關於歷組與賓組命辭有著不同慣例的說法提出質疑。此文的研究依據一個很大程度上可視爲客 觀準則的觀點，即通常所謂的“前提假設”，也就是任何話語、句子所包含的預設。本文亦將涉及“其”及“其”的否 定形式的討論。

\section{關鍵字}

占卜慣例 - 甲骨文 - 語法 - 預設 - 其 